\title{
Detection of B -Human Chorionic Gonadotrophin in Vaginal Fluid For The Diagnosis of Preterm Premature Rupture of Membranes
}

\author{
* Ahmed Hamza Awad, ** Mohamed Ibrahim El-Mohandes,** Mahmoud Nahedd mushtaha \\ *Department of Obstetrics and Gynecology, Faculty of Medicine, Al-Azhar University, **Department \\ of Obstetrics and Gynecology, El-Galaa Maternity Teaching Hospital, Cairo.
}

\begin{abstract}
:
Background: The purpose of the present study is to evaluate $\beta$-hCG in vaginal washing fluid for the diagnosis of preterm premature rupture of membranes (PROM).

Methods: This clinical trial was carried out at El-Galaa Maternity Teaching Hospital. The study included 100 women who were in their $3^{\text {rd }}$ trimester of pregnancy. They were divided into 2 groups; group I (case group): Pregnant women with definite history of premature rupture of membranes confirmed by speculum examination as patients' (PROM) group. $(\mathrm{n}=50)$ and group II (control group): Pregnant women with no history of rupture of membranes as control group. $(n=50)$

Results: There was significant statistical difference in the prediction of PROM between the case group and the control group.

Conclusion: The presence of vaginal HCG is highly predictive of membranes rupture and is a more accurate diagnostic test than the amniotic fluid index (AFI) assessment in the diagnosis of ROM. Keywords: $\beta$-hCG, Premature Rupture of Membranes.
\end{abstract}

\section{Introduction}

Premature rupture of the fetal membranes $(\mathrm{PROM})$ is defined as rupture of amniotic membranes and amniotic fluid leakage, $1 \mathrm{~h}$ or more prior to the onset of labor. PROM is divided into two categories including term PROM (PROM after 37 weeks of gestation) and preterm PROM (PPROM) (before 37 weeks of gestation $)^{(1)}$.

PROM occurs in approximately $10 \%$ of all pregnancies after 37 weeks gestation and in 2$3.5 \%$ of pregnancies before 37 weeks gestation. The diagnosis of rupture of the membranes (ROM) may be made by clinical history and some simple diagnostic tests. Patient history is accurate for about $90 \%$ for the diagnosis and should not be ignored ${ }^{(2)}$.

Regarding the necessity for accurate diagnosis of preterm premature rupture of membranes (PPROM), several diagnostic tests have been suggested. Nitrazine test, fern test, and ultrasound have been considered as very useful tests ${ }^{(3)}$.

Biochemical tests have also been suggested, but should only be performed in cases of very suspicious ROM, which other simple tests may not diagnose accurately. One of biochemical materials (substances) which have high concentrations in amniotic fluid is $\beta$-human chorionic gonadotropin ( $\beta$-hCG), which is secreted solely by syncytiotrophoblasts and can be found in mother's blood or urine and has been studied for the evaluation of $\mathrm{ROM}^{(4)}$.

\section{Patient and methods:}

This study was designed for pregnant women attending Al-Galaa Maternity Teaching Hospital in their $3^{\text {rd }}$ trimester of pregnancy with gestational age between 28 and 40 weeks from March 2018 to November 2018. The study was approved by Al-Azhar University Ethics Board.

This study included 100 pregnant women who were admitted to the hospital. They were divided into 2 groups. Group I (case group): Pregnant women with definite history of premature rupture of membranes confirmed by speculum examination as patients' (PROM) group. ( $n=50)$. Group II (control group): Pregnant women with no history of rupture of membranes as control group. $(n=50)$

\section{Study Procedures:}

- Informed consent for study procedure and patient counseling

- History taking for last menstrual period, leak of vaginal fluid and labor pain, take sure dates and early ultrasound document if unsure of dates.

- General examination for blood pressure, pulse and temperature, and routine investigations.

- Sterile Cusco speculum examination.

- Ultrasonographic examination for gestational age and amniotic fluid index (AFI) calculation for correlation with the diagnosis 
of preterm premature rupture of membranes patients.

- The amniotic fluid index (AFI) was assessed in four quadrants; according to the method of Phelan ${ }^{(5)}$. This was calculated by adding the vertical depths of the largest pocket in each of four equal uterine quadrants

\section{Inclusion criteria included:}

1- Age from 18-35 years.

2- Gestational age between $28-40$ wks.

3- Absence of regular uterine contractions.

4- Definite history of premature rupture of membranes with pooling of amniotic fluid (AF) in the posterior vaginal fornix during sterile speculum examination. (Group I)

\section{Exclusion criteria included:}

1- Patients with multiple pregnancies and anomalous fetuses.

2- Presence of any amount of vaginal bleeding, either spontaneous or traumatic due to speculum examination.

3- History of coitus in last $48 \mathrm{hrs}$.

4- Pregnancy complicated by oligohydraminos such as pregnancy induced HTN, IUGR and post-term pregnancy

5- Presence of vaginal infections.

\section{Sample size:}

A sample of 50 cases per group was done using computer program SPSS (Statistical Package for the Social Science; SPSS Inc., Chicago, IL, USA) release 15 for Microsoft Windows (2006) (6).

\section{Statistical methods :}

Data were statistically described in terms of mean \pm standard deviation ( $\pm \mathrm{SD}$ ), median and range, or frequencies (number of cases) and percentages when appropriate. Comparison of numerical variables between the study groups was done using Student $t$ test for independent samples. For comparing categorical data, Chi square $\left(\chi^{2}\right)$ test was performed. Exact test was used instead when the expected frequency is less than 5. Accuracy was represented using the terms sensitivity, specificity, +ve predictive value, -ve predictive value, and overall accuracy. Receiver operator characteristic (ROC) analysis was used to determine the optimum cut off value for the studied diagnostic markers. $p$ values less than 0.05 was considered statistically significant. All statistical calculations were done using computer program SPSS (Statistical Package for the Social Science; SPSS Inc., Chicago, IL, USA) release 15 for Microsoft Windows $(2006)^{(6)}$.

\section{Results:}

Table (1): Clinical characteristics of the patients.

\begin{tabular}{|l|l|l|l|l|l|l|l|}
\hline \multirow{2}{*}{ Characteristics } & \multicolumn{2}{l|}{$\begin{array}{l}\text { PROM group } \\
(n=50)\end{array}$} & \multicolumn{2}{l|}{$\begin{array}{l}\text { Control group } \\
(n=50)\end{array}$} \\
\cline { 2 - 8 } & Mean & \pm SD & Range & Mean & \pm SD & Range & \\
\hline Maternal age (yrs) & 28.98 & \pm 5.829 & $17-40$ & 27.82 & \pm 6.445 & $16-40$ & 0.348 \\
\hline $\begin{array}{l}\text { Calculated gestational } \\
\text { age (wks) }\end{array}$ & 36.3 & \pm 2.720 & $29-40$ & 38.2 & \pm 1.262 & $36-40$ & $<0.05$ \\
\hline $\begin{array}{l}\text { Gestational age by } \\
\text { ultrasound (wks) }\end{array}$ & 35.68 & \pm 2.394 & $28-40$ & 37.36 & \pm 0.985 & $36-40$ & $<0.05$ \\
\hline
\end{tabular}

Table (2): Efficacy of vaginal $\beta$-HCG cutoff value of $54 \mathrm{mIU} / \mathrm{ml}$ in diagnosis of rupture of membranes.

\begin{tabular}{|l|l|l|l|}
\hline \hline p-HCG & PROM group $N(\%)$ & Control group $N(\%)$ & Total \\
\hline B-HCG $\geq \mathbf{5 4} \mathbf{~ m I U ~} / \mathbf{m L}(+)$ & $45(90 \%)$ & $3(6 \%)$ & 48 \\
\hline B-HCG $<\mathbf{5 4} \mathbf{~ I I U / m L ~ ( - )}$ & $5(10 \%)$ & $47(94 \%)$ & 52 \\
\hline TOTAL & 50 & 50 & 100 \\
\hline
\end{tabular}

This table shows best cutoff value of $\beta$-HCG $=54 \mathrm{mIU} / \mathrm{ml}$ by which we can measure sensitivity, specificity, PPV \& NPV of $\beta$-HCG in the diagnosis of PROM.
The results were in agreement with the previous studies and receiver operating characteristic (ROC) curve for vaginal $\beta$-HCG worths in diagnosing of premature rupture of membranes 
was incontestable that a $\beta$-HCG cutoff value of $54 \mathrm{mIU} / \mathrm{mL}$ optimally identified patients with membranes rupture.

\section{Discussion}

This study was a case-control prospective study that was done to estimate the diagnostic potential of human chorionic gonadotropin (HCG) measure in vaginal fluids as an indicator of rupture of fetal membranes (ROM) and compare the diagnostic worth of fast $3 \mathrm{HCG}$ dipsticks and human chorionic gonadotropin ELISA within the cervicovaginal secretions for identification of PROM.

Also, comparison of the effectuality of human chorionic gonadotropin measuring and amnionic fluid index (AFI) assessment with the diagnosing of ROM.

Pooling of waters within the posterior vaginal fornix during speculum examination was used because it is the gold standard so as to be able to calculate the sensitivity, specificity, positive predictive worth and negative predictive worth of the test. There were no statistically significant variations in maternal age and parity between patients with and without clinical proof of membranes rupture. Though there was statistically significant variations between the studied groups as regard the calculated fetal age and also the ultrasonographic GA however it has no clinical importance as there was not an outsized distinction between the average in each.

In the present study, it was found that human chorionic gonadotropin had $90^{\text {th }}$ diagnostic sensitivity, 94 diagnostic specificity, $93.75 \%$ PPV and $90.38 \%$ NPV. This is in agreement with the previous studies and receiver operating characteristic (ROC) curve for vaginal $\beta$-HCG worths in diagnosing of premature rupture of membranes was incontestable that a $\beta-\mathrm{HCG}$ cutoff value of $54 \mathrm{mIU} / \mathrm{mL}$ optimally identified patients with membranes rupture.The performance of this marker in identification PROM was thus excellent. Additionally fast pregnancy \{test|bioassay\}; a fast and simple accessible test was found to have the foremost sensitivity $92.16 \%$ and diagnostic specificity $88 \%, 88.68 \%$ PPV, $91.67 \%$ NPP and 90.10 accuracy therefore it's a fast, low cost and accurate test. The diagnostic power of a test is considered acceptable if all diagnostic parameters (e.g. sensitivity, specificity, PPV and NPV) are more than $80 \%{ }^{(7)}$.

In the literature, to our data, there are several published studies associated with HCG in vaginal fluid for the identification of PROM. In the study of Takanabu and Yuichirou in Japan, 188 control patients and twenty four confirmed PROM patients were enclosed and median values of $\beta$-HCG consistent with the trimesters of gestation were determined. In line with the assumed threshold worth of vaginal wash fluid $\beta$ HCG that is taken into account as fifty $\mathrm{mIU} / \mathrm{mL}$ sensitivity, specificity and PPV of gonadotrophin in diagnosing of rupture of membranes were seventy fifth, ninety seven and ninety fifth respectively ${ }^{(8)}$. Therefore, these authors concluded that gonadotrophin is a perfect marker for amniotic fluid and speedy tests for its measure in vaginal fluid may offer a reliable tool for detection of ruptured fetal membranes, if less than twelve hours have pass on since the leak of waters into the vagina.

\section{References}

1. Bahasadri S, Kashanian M, Khalili $S$ (2013): Evaluation of vaginal fluid $\beta$ human chorionic gonadotrophin for the diagnosis of preterm premature rupture of membranes. J Obstet Gynaecol Res.,39 (4):777-82.

2. Simhan HN, Canavan TP (2005) : Preterm premature rupture of membranes: Diagnosis, evaluation and management strategies.BJOG., 112 (1): 32-37.

3. Canavan TP, Simhan HN, Caritis $\mathbf{S}$ (2004): An evidence-based approach to the evaluation and treatment of premature rupture of membranes: Part I. Obstet Gynecol Surv., 59:669-677.

4. Shahin M, Raslan H (2007): Comparative study of three amniotic fluid markers in premature rupture of membranes: Prolactin, beta subunit of human chorionic gonadotropin, and alpha-fetoprotein. Gynecol Obstet Invest., 63: 195-199.

5. Phelan J P, Ahn M O, Smith C V et al. (1987): Amniotic fluid index measurements during pregnancy. J Reprod Med., 32:601-604.

6. Miller MC and Knapp RG (1992): Clinical epidemiology and biostatistics; $3^{\text {rd }}$ 
Detection of B -Human Chorionic Gonadotrophin in Vaginal Fluid...

edition, published by Williams \& Wilkins, Maryland.
7. Nili F, Shams A (2003): Neonatal complications of premature rupture of membrane. Acta Medica Iranica, 41:175-9.

8. Takanabu $F$ and Yuichirou $S$ (1997): Vaginal fluid HCG levels for detecting PROM. Obstet Gyncol., 1997:89-2:261-4. 